\title{
Neutrophil-to-lymphocyte ratio as a prognostic biomarker in hepatocellular carcinoma after transarterial chemoembolization
}

\author{
Soung Won Jeong^ \\ Division of Gastroenterology and Hepatology, Department of Internal Medicine, Soonchunhyang University Seoul Hospital, Soonchunhyang \\ University College of Medicine, Seoul, Korea \\ Correspondence to: Soung Won Jeong. Division of Gastroenterology and Hepatology, Department of Internal Medicine, Soonchunhyang University \\ Seoul Hospital, Soonchunhyang University College of Medicine, 59 Daesagwan-ro, Yongsan-gu, Seoul 04401, Korea. Email: jeongsw@schmc.ac.kr. \\ Comment on: Wang C, Wang M, Zhang X, et al. The neutrophil-to-lymphocyte ratio is a predictive factor for the survival of patients with \\ hepatocellular carcinoma undergoing transarterial chemoembolization. Ann Transl Med 2020;8:541.
}

Submitted May 27, 2020. Accepted for publication Jun 08, 2020.

doi: $10.21037 /$ atm-20-4296

View this article at: http://dx.doi.org/10.21037/atm-20-4296

Hepatocellular carcinoma (HCC) is the fifth most common cancer globally and the third leading cause of cancer-related deaths, in accordance with the World Health Organization (globacan.iarc.fr).

HCC is an inflammation-related malignancy, mainly associated with hepatitis $\mathrm{B}$ or hepatitis $\mathrm{C}$ viral infections. Transarterial chemoembolization (TACE) is considered for intermediate-stage HCC that is not eligible for curative treatment options $(1,2)$. Tumor size, number of tumors, $\alpha$-fetoprotein (AFP) level, Child-Turcotte-Pugh score, vascular invasion and tumor response have been identified as significant factors predicting overall survival (OS) in HCC patients treated with TACE (3-6). However, the identification of robust prognostic markers is required for the precise prediction of response to TACE in HCC patients. Serum parameters are among the most promising biomarkers of HCC recurrence and survival, as they are readily available, and their measurement can be performed rapidly and affordably.

Recently, elevated peripheral neutrophil-lymphocyte ratio (NLR) has been reported as an indicative marker of poor OS in various cancers $(7,8)$. High NLR has also been associated with poor survival in HCC patients undergoing locoregional therapy, including TACE (9-12), resection $(13,14)$ and radiofrequency ablation (RFA) $(15,16)$. A recent study in this journal by Wang et al. (17) demonstrated that NLR >2.4 in baseline was an independent prognostic indicator of poor OS. A high NLR one month after TACE has also been related with poor prognosis. The results showed that elevated NLR was associated with large tumor size, high levels of total bilirubin and aspartate transaminase, and low red blood cell counts. These associations might be attributed to the inflammatory responses induced by large tumors, resulting in a high NLR.

Systemic inflammation has been associated with poor prognosis in multiple cancer entities. Inflammatory responses in the tumor microenvironment play important roles in cancer cell proliferation and tumor progression $(18,19)$.

As a marker of systemic inflammation, the NLR has been associated to cancer progression, metastasis, and prognosis in various tumors. Notably, neutrophils, which are the main factor of the inflammatory tumor microenvironment, are closely associated with tumor cell proliferation and survival, as well as tumor angiogenesis, metastasis, and disruption of the acquired immune system (20). Meanwhile, lymphocytes are key players in cancer immune surveillance, suppressing tumor progression (21). Importantly, decreased lymphocyte counts have been associated with impaired antitumor immune responses, enabling tumor progression and metastasis (22). Hence, lymphocytes and neutrophils exert opposing functions in inflammatory responses and cancer progression.

$\wedge$ ORCID: 0000-0003-2855-6011. 
There are several issues in this study. First, the baseline NLR cut-off value used in this study was 2.4. However, the baseline NLR cut-off values are different in each study (23). Different NLRs applied to each center make various data and confused for clinical use. Thus, large cohort studies are required to establish the most appropriate NLR cut-off value, which provides good sensitivity and specificity. Second, tumor response after TACE is an important predictor of OS; thus, it is crucial to assess its relationship with other predictive factors. Although this was a retrospective study, the analysis of tumor response could have enabled the determination of the predictive value of NLR. Third, in this study, authors identified the baseline NLR as an independent predictor of poor OS. Although NLR has been suggested as a treatment response marker, it remains unclear whether NLR can distinguish between tumor size and number of lesions. Future studies are required to assess the predictive value of NLR in cohorts stratified according to the tumor size and the number of lesions.

Fourth, various following treatments including hepatic resection, RFA, systemic chemotherapy, radiation, and conservative treatment might be conducted after the TACE, and the effect of these subsequent treatments should be considered as a limitation for the analysis.

Currently, NLR with other combined factors such as plate to lymphocyte ratio (9), aspartate aminotransferaseto-alanine aminotransferase ratio (24), or C-reactive protein to albumin ratio (25), have been identified to promote the survival prediction after TACE. Additionally, prognostic score including NLR was noticeable comparing with the prior scores (12).

In conclusion, baseline NLR and its dynamic changes during therapy can predict OS in HCC patients treated with TACE. NLR may be a simple, available, inexpensive and reliable predictive marker for HCC. Furthermore, the combination of NLR with other predictive factors or the development of a prognostic score using NLR could improve the prognostic prediction. However, the appropriate cut-off value of NLR should be established in a large cohort study.

\section{Acknowledgments}

Funding: This work was supported by the National Research Foundation of Korea (NRF) grant funded by the Korea government (Ministry of Science and ICT) (2020R1F1A1076282) and Soonchunhyang University
Research Fund.

\section{Footnote}

Provenance and Peer Review: This article was commissioned by the editorial office, Annals of Translational Medicine. The article did not undergo external peer review.

Conflicts of Interest: The author has completed the ICMJE uniform disclosure form (available at http://dx.doi. org/10.21037/atm-20-4296). The author has no conflicts of interest to declare.

Ethical Statement: The author is accountable for all aspects of the work in ensuring that questions related to the accuracy or integrity of any part of the work are appropriately investigated and resolved.

Open Access Statement: This is an Open Access article distributed in accordance with the Creative Commons Attribution-NonCommercial-NoDerivs 4.0 International License (CC BY-NC-ND 4.0), which permits the noncommercial replication and distribution of the article with the strict proviso that no changes or edits are made and the original work is properly cited (including links to both the formal publication through the relevant DOI and the license). See: https://creativecommons.org/licenses/by-nc-nd/4.0/.

\section{References}

1. Marrero JA, Kulik LM, Sirlin CB, et al. Diagnosis, Staging, and Management of Hepatocellular Carcinoma: 2018 Practice Guidance by the American Association for the Study of Liver Diseases. Hepatology 2018;68:723-50.

2. Lee JS, Kim BK, Kim SU, et al. A survey on transarterial chemoembolization refractoriness and a real-world treatment pattern for hepatocellular carcinoma in Korea. Clin Mol Hepatol 2020;26:24-32.

3. Jeong SO, Kim EB, Jeong SW, et al. Predictive Factors for Complete Response and Recurrence after Transarterial Chemoembolization in Hepatocellular Carcinoma. Gut Liver 2017;11:409-16.

4. Cerban R, Ester C, Iacob S, et al. Predictive Factors of Tumor Recurrence and Survival in Patients with Hepatocellular Carcinoma treated with Transarterial Chemoembolization. J Gastrointestin Liver Dis 2018;27:409-17.

5. Hucke F, Pinter M, Graziadei I, et al. How to STATE 
suitability and START transarterial chemoembolization in patients with intermediate stage hepatocellular carcinoma. J Hepatol 2014;61:1287-96.

6. Kim DY, Ryu HJ, Choi JY, et al. Radiological response predicts survival following transarterial chemoembolisation in patients with unresectable hepatocellular carcinoma. Aliment Pharmacol Ther 2012;35:1343-50.

7. Mei Z, Shi L, Wang B, et al. Prognostic role of pretreatment blood neutrophil-to-lymphocyte ratio in advanced cancer survivors: A systematic review and meta-analysis of 66 cohort studies. Cancer Treat Rev 2017;58:1-13.

8. Templeton AJ, McNamara MG, Seruga B, et al. Prognostic role of neutrophil-to-lymphocyte ratio in solid tumors: a systematic review and meta-analysis. J Natl Cancer Inst 2014;106:dju124.

9. Fan W, Zhang Y, Wang Y, et al. Neutrophil-to-lymphocyte and platelet-to-lymphocyte ratios as predictors of survival and metastasis for recurrent hepatocellular carcinoma after transarterial chemoembolization. PLoS One 2015;10:e0119312.

10. Zhou D, Liang J, Xu LI, et al. Derived neutrophil to lymphocyte ratio predicts prognosis for patients with $\mathrm{HBV}$ associated hepatocellular carcinoma following transarterial chemoembolization. Oncol Lett 2016;11:2987-94.

11. He C, Zhang Y, Cai Z, et al. The prognostic and predictive value of the combination of the neutrophil-tolymphocyte ratio and the platelet-to-lymphocyte ratio in patients with hepatocellular carcinoma who receive transarterial chemoembolization therapy. Cancer Manag Res 2019;11:1391-400.

12. Chon YE, Park H, Hyun HK, et al. Development of a New Nomogram Including Neutrophil-to-Lymphocyte Ratio to Predict Survival in Patients with Hepatocellular Carcinoma Undergoing Transarterial Chemoembolization. Cancers (Basel) 2019;11:509.

13. Liao R, Tang ZW, Li DW, et al. Preoperative neutrophilto-lymphocyte ratio predicts recurrence of patients with single-nodule small hepatocellular carcinoma following curative resection: a retrospective report. World J Surg Oncol 2015;13:265.

14. Wang D, Bai N, Hu X, et al. Preoperative inflammatory

Cite this article as: Jeong SW. Neutrophil-to-lymphocyte ratio as a prognostic biomarker in hepatocellular carcinoma after transarterial chemoembolization. Ann Transl Med 2020;8(18):1124. doi: 10.21037/atm-20-4296 markers of NLR and PLR as indicators of poor prognosis in resectable HCC. PeerJ 2019;7:e7132.

15. Tan W, Sun W, Li X, et al. Preablation neutrophil-tolymphocyte ratio as an independent prognostic factor in locally advanced hepatocellular carcinoma patients following radiofrequency ablation. J Cancer Res Ther 2018;14:84-9.

16. Chen K, Zhan MX, Hu BS, et al. Combination of the neutrophil to lymphocyte ratio and the platelet to lymphocyte ratio as a useful predictor for recurrence following radiofrequency ablation of hepatocellular carcinoma. Oncol Lett 2018;15:315-23.

17. Wang C, Wang M, Zhang X, et al. The neutrophil-tolymphocyte ratio is a predictive factor for the survival of patients with hepatocellular carcinoma undergoing transarterial chemoembolization. Ann Transl Med 2020;8:541.

18. Coussens LM, Werb Z. Inflammation and cancer. Nature 2002;420:860-7.

19. Grivennikov SI, Greten FR, Karin M. Immunity, inflammation, and cancer. Cell 2010;140:883-99.

20. Powell DR, Huttenlocher A. Neutrophils in the Tumor Microenvironment. Trends Immunol 2016;37:41-52.

21. Dunn GP, Old LJ, Schreiber RD. The immunobiology of cancer immunosurveillance and immunoediting. Immunity 2004;21:137-48.

22. Stotz M, Pichler M, Absenger G, et al. The preoperative lymphocyte to monocyte ratio predicts clinical outcome in patients with stage III colon cancer. Br J Cancer 2014;110:435-40.

23. Xiao WK, Chen D, Li SQ, et al. Prognostic significance of neutrophil-lymphocyte ratio in hepatocellular carcinoma: a meta-analysis. BMC Cancer 2014;14:117.

24. Liu C, Jia BS, Zou BW, et al. Neutrophil-to-lymphocyte and aspartate-to-alanine aminotransferase ratios predict hepatocellular carcinoma prognosis after transarterial embolization. Medicine (Baltimore) 2017;96:e8512.

25. Shen Y, Wang H, Li W, et al. Prognostic significance of the CRP/Alb and neutrophil to lymphocyte ratios in hepatocellular carcinoma patients undergoing TACE and RFA. J Clin Lab Anal 2019;33:e22999. 